\title{
Syndromic Surveillance Data for Accidental Fall Injury
}

\author{
Donald E. Brannen*, Melissa Howell, Ashley Steveley, Jeff Webb, and Deidre Owsley \\ Greene County Public Health, Xenia, Ohio
}

\begin{abstract}
Background:

Fall injuries (FI) are a priority for public health planning. Syndromic surveillance (SS) is used to detect outbreaks, environmental exposures, and bioterrorism in real time. Since information is gathered on patients, the utility of using this system for Fl should be evaluated.

\section{Methods:}

Strategies to integrate $\mathrm{FI}$ medical and SS data were compared using a cohort versus case control (CC) study design.
\end{abstract}

Results:

The CC study was accurate $77.7 \%$ (57.7-91.3) of the time versus $100 \%$ for a cohort design. The CC study design found Fl increased for older age groups, female gender, November, and December months. Dates with any freezing temperature had a higher case fatality rate. Repeat acute care visits increased the risk of $\mathrm{Fl}$ diagnosis by over $6 \%$ and trended upward with each visit $(\mathrm{R}=.333$, $\mathrm{p}<.001)$.

\section{Conclusions:}

The CC diagnostic quality of FI were better for age and gender than for area. The $\mathrm{CC}$ study found the indicators of increased risk of $\mathrm{Fl}$ including freezing temperature, repeat acute care visits, older age groups, female gender, November, and December months. A gradient of increasing odds of FI with the number of acute care visits provides proof that community fall prevention programs should focus on those most likely to fall. A CC design of SS data can quickly identify indicators of FI with a lower accuracy but with less cost than a full cohort study, thus providing a method to focus local public health interventions.

Key words: Accidental Falls, Public Health Surveillance, Case Control, Risk Factors

*Corresponding Author: Donald E. Brannen • 360 Wilson Drive, Xenia, Ohio 45385 • 937 374-5600 • dbrannen@gcph.info

DOI: $10.5210 /$ ojphi.v13i3.10264

Copyright @2021 the author(s)

This is an Open Access article. Authors own copyright of their articles appearing in the Online Journal of Public Health Informatics. Readers may copy articles without permission of the copyright owner(s), as long as the author and OJPHI are acknowledged in the copy and the copy is used for educational, not-for-profit purposes.

\section{INTRODUCTION}

The 2019 Community Health Needs Assessment for Southwest Ohio had the rate of injury deaths as the top health priority [1]. There was wide variability among the 25 counties assessed, 
with injury deaths ranging from 45.5 up to 97.6 per 100,000, higher than the national rate of 45.3. The Greene County Community Health Assessment (CHA) reported that elderly residents and $12 \%$ of the county's population was at higher risk for injuries, emergency room visits, hospitalizations, and mortality associated with accidental falls than Ohio [2]. Based on these findings, the Greene County Community Health Improvement Plan (CHIP) 2017 had injury prevention as a top priority [3]. The CHIP prioritized root causes of death and morbidity from falls as chronic disease, inactivity, and living alone. One of the CHIP's cross-cutting strategies to address fall related morbidity and mortality is to integrate public health data with the health care system's data. This strategy is consistent with research findings that found syndromic surveillance data for injuries, including fall related injuries to be strongly correlated to hospital discharge diagnoses [4].

In Ohio, traumatic injury surveillance, including injuries from accidental falls, is conducted using an automated syndromic surveillance system called EpiCenter [5]. Mortality data became 'routinely' available through Ohio Department of Health's (ODH) secure data warehouse to local health departments in 2018 [6]. The risk of falls during hospitalizations has been 2.08 times higher risk for persons with a history of falls [7]. Evaluations of falls due to weather have found that time of day and snow was a predictor of emergency department care for fall related injuries [8].

Several issues arise when conducting small area analysis on surveillance data. The resident's zip code provides a key to geocoding the health events observed. Using population denominators for zip codes is a viable strategy but methodological issues arise with cases within a zip code area that crosses jurisdictional boundaries. The census bureau does provide rate estimates within jurisdiction population counts, for example, by county, for the decennial census. These rate estimates can be applied to the population estimates to estimate denominators. This requires time that may make interventions irrelevant if the intervention is delayed in its implementation. A case control study of accidental falls that draws controls from all other traumatic injuries would alleviate the need for these extra computational steps that a cohort study would otherwise require. The denominators in a case control study could be all the traumatic injuries extracted matched by area and a time variable in order to calculate the odds of accidental falls. Otherwise, population counts would have to be estimated for each area studied in order to determine risk.

Using the traumatic injury data from syndromic surveillance data to conduct an unmatched case control study versus having to calculate risk of injury data from acute care interactions using population level denominators would enhance efficiency if the results were comparable. Persons requiring emergency department treatment for falls compared to hospital inpatient and outpatient discharge data have been done [7], but there has not been a cohort study design that compared the risk of injuries from falls within the population versus a more efficient casecontrol of fall injuries using all other traumatic injuries requiring acute care. A case control study that is matched by time of injury would allow for identification of the effects of the type of weather at the time of injury, estimation of the risk of repeated visits on acute care, and identification of indicators for increased risk for traumatic injury from falls.

The goal of this current study was to evaluate the diagnostic efficacy of a more efficient case control study compared to a cohort analysis for county level surveillance of accidental fall injuries. The specificity, sensitivity, and accuracy of the case-control odds ratio of injury from accidental falls was compared to the population risk ratio to determine if traumatic injury discharge diagnosis can adequately provide population level surveillance without population 
level census data. Other goals are to estimate the risk of repeat acute care interactions on accidental fall injuries and provide an estimate the impact of the weather on the risk of injuries from falls.

\section{METHODS}

Setting: Acute care interactions for traumatic injuries and all fall related deaths among all residents of Greene County for the 2018 year. All the traumatic injuries that occurred within Greene County, Ohio residents that sought acute care within Ohio during 2018 were included in the study design.

Design: An observational comparison of case control and cohort study design.

Participants (inclusion, exclusion criteria), recruitment process: Participants were all residents of Greene County, Ohio. Cases were any fall related injury requiring acute care treatment. Controls were persons with a non-fall associated traumatic injury. For the cohort analysis, the controls were all residents that were not diagnosed with a traumatic injury or had a fall injury as an underlying cause of death. Persons were excluded as cases if they had acute care for their injury outside of Ohio. Cases were defined as those traumatic injuries that had discharge ICD 10 codes W00 through W19 for 'accidental fall'. Indicator variables were created for each code as ' 1 ' if the code was found and ' 0 ' if the code was not found. For the case-control study, those coded as zero were identified as controls. For the cohort study, population denominators were identified from census data for zip code areas, sex, and age groupings.

Procedures: No clinical procedures were conducted.

Measures/outcomes: Odds and risk ratios along with specificity, sensitivity, and accuracy of the case control versus the cohort study designs.

Statistical analysis: The daily climate data was downloaded from the National Centers for Environmental Information in order to assess the risk of injury from falls [9]. This was used to calculate the odds of fall injury during any day with a minimum daily temperature at or below freezing $0{ }^{\circ} \mathrm{C}, 32^{\circ} \mathrm{F}$. The odds ratio was calculated after matching cases and controls by month and date. The case fatality ratio was calculated as the rate per 100,000 of deaths divided by the rate per 100,000 of injuries from accidental falls multiplied by 100 .

Validation of the syndromic surveillance system's capability to identify traumatic injuries is outside the scope of this evaluation, the agreement between the free text search for accidental fall injury and the ICD 10 diagnostic code provides an indication of internal validity of the result. Cohen's kappa was calculated to measure the agreement between the presence of the free text and the presence of any 'accidental fall' ICD 10 diagnostic code at discharge for the same visit. A value of 1 indicates perfect agreement. A value of 0 indicates that agreement is no better than chance. Kappa is based on a square table in which row and column values represent the same scale. Any cell that has observed values for one variable but not the other is assigned a count of 0. Cohen's Kappa was calculated to determine the level of agreement between the free text field in the medical record and the discharge diagnosis. Any mention of 'Fall','Fell', 'fell', or 'fall' was searched for.

The injury rates from accidental falls per 100,000 was compared to the risk and odd ratios to determine if there are congruencies among the results. This is to determine if traumatic injury 
discharge diagnosis can adequately provide population level surveillance in the absence of population level census data. The level of agreement was the cutoff rate per 100,000 where the rank per predictor variable is not identified as a risk factor for fall injury. The odds ratio versus the risk ratio for the total population was evaluated for the diagnostic adequacy of syndromic surveillance data of traumatic injuries as controls versus population estimates of the risk factor variables. Sensitivity, specificity and accuracy of the odds ratio to predict risk was assessed. Protective ratios (those not including one) was coded as negative test results, no difference (those ratios with confidence intervals including one) was coded as 'negative', and those ratios with confidence limits above one was coded as 'positive'. The following definitions was used: Sensitivity: probability that a test result was positive when the disease is present (true positive rate $)=a /(a+b)$; Specificity: probability that a test result was negative when the disease is not present (true negative rate) $=\mathrm{d} /(\mathrm{c}+\mathrm{d})$; Accuracy: overall probability that a patient was correctly classified $=(a+d) /(a+b+d+c)$. The impact of repeat injury trauma requiring acute care on the risk associated accidental fall injury was assessed by regression of the number of repeats with the dependent variable being the present or absence of a diagnosis at discharge for accidental fall with the constant set to zero.

The accidental falls by gender was assessed while controlling for age. Risk ratios was calculated for each age strata by gender. To assess the impact of repeat visits for acute care on accidental fall morbidity, any repeat visit for acute care was coded as 1 and the odds ratio was assessed. Any other person seeking acute care for traumatic injury was used as a control to assess the impact of acute care on accidental fall morbidity. Institutional review board approval was not required as it was conducted under the duties of health departments in Ohio to study the prevalence of disease and health conditions within its district, which may be released in summary, statistical, or aggregate form (Ohio Revised Codes 3709.22 and 3701.23).

\section{RESULTS}

\section{Cohen's Kappa Results}

The syndromic surveillance data was searched for any ICD 10 code that indicated an accidental fall among the discharge diagnoses with subjects drawn from those with any traumatic injury during 2018. Given that the algorithm for traumatic injury may and should include other types of injury than accidental injury a separate check of the extracted data's free text primary complaint free text field for any mention of the terms of 'fall' or 'fell' and their plural or punctuation derivatives. The cross tabulation of the concordance or discordance of diagnostic codes with free text reasons for the acute care interaction associated with any falls with the ICD 10 Codes for accidental fall W00-W19 was tabulated. The counts for any fall injury and any free text mention was 11,634 (no fall injury-no free text), 3,097 (no fall injury-free text), 372 (fall injury-no free text reason), and 1,403 (fall injury-free text). Public health surveillance of acute care interactions uses algorithms to search the plain language primary reason for the health care visit and classify the visit according syndromes. The syndrome of interest in this study is the traumatic injury syndrome. The free text reason for the acute care interaction that mentioned falls was highly associated with any ICD 10 indicating an accidental fall with a Cohen's Kappa measure of agreement value of $0.346(p<.001)$.

\section{Repeat Acute Care Interactions Effect on Risk of Accidental Fall Injuries}

The frequency of acute care interactions in the study population is shown in Figure 1. The regression analysis revealed that repeat acute care visits explained $33.3 \%$ of the variance of all traumatic injury visits $(\mathrm{R}=.333$ for linear regression through the origin, $\mathrm{p}<.001)$. With every 
injury trauma requiring acute care, the risk that the trauma has an associated accidental fall injury increased by $6.47 \%$ (95\% confidence interval 6.2-6.8).

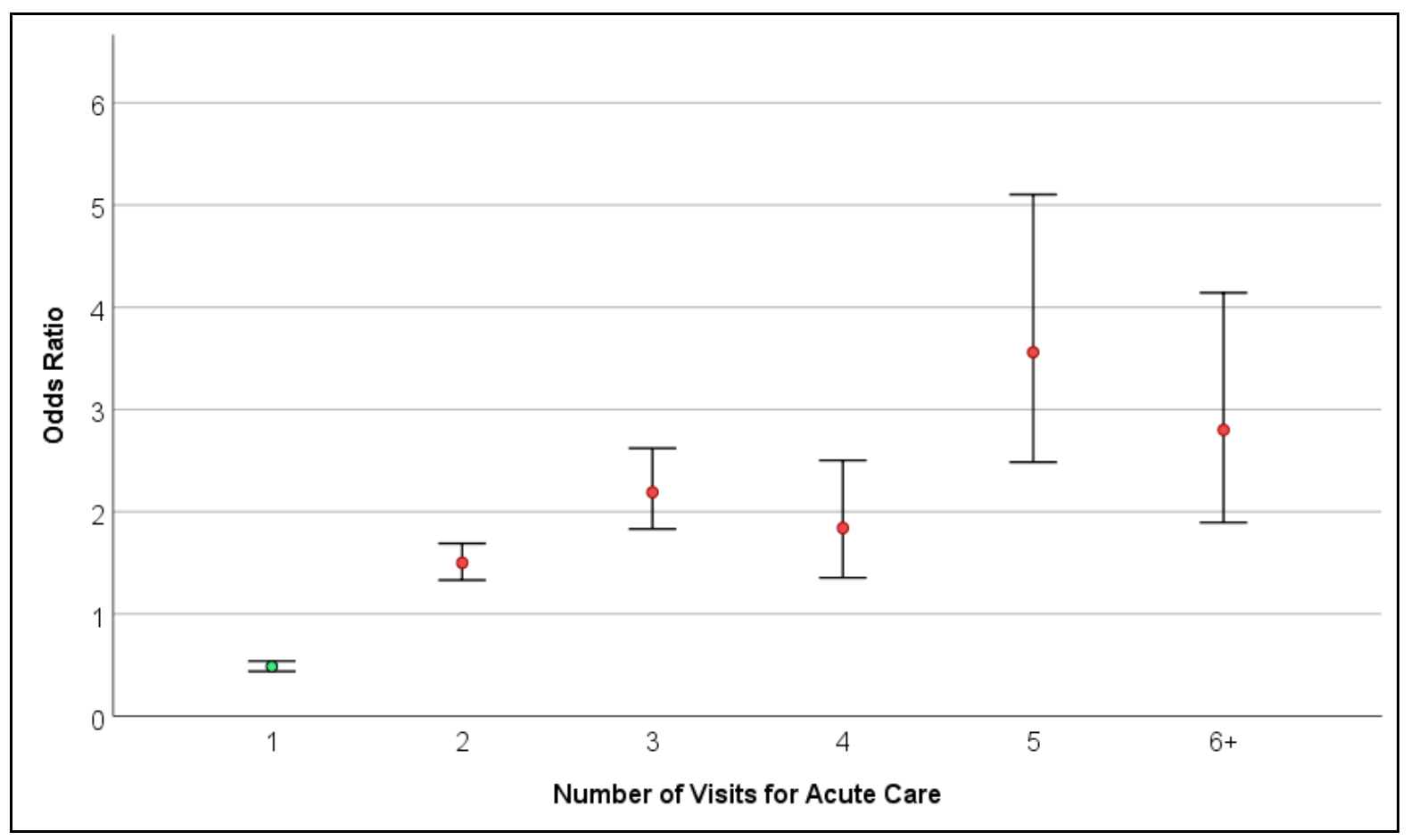

Figure 1. Odds of Accidental Fall Diagnosis Among All Traumatic Injuries Seeking Acute Care by Number of Visits for Acute Care during 2018 Among Greene County Residents.

\section{Impact of Weather on the Risk of Injuries from Falls}

When injuries are matched by month of occurrence, November and December are significant (see Table Odds of Fall Injury by Month). While the unadjusted odds ratio 'day of year with any freezing temperature' was not significant, the fall injury rate during days with freezing weather was elevated at 315 per 100,000. The deaths from fall injuries during days with freezing weather was 10 per 100,000 . The case fatality rate for days with freezing weather was $3.2 \%$. 


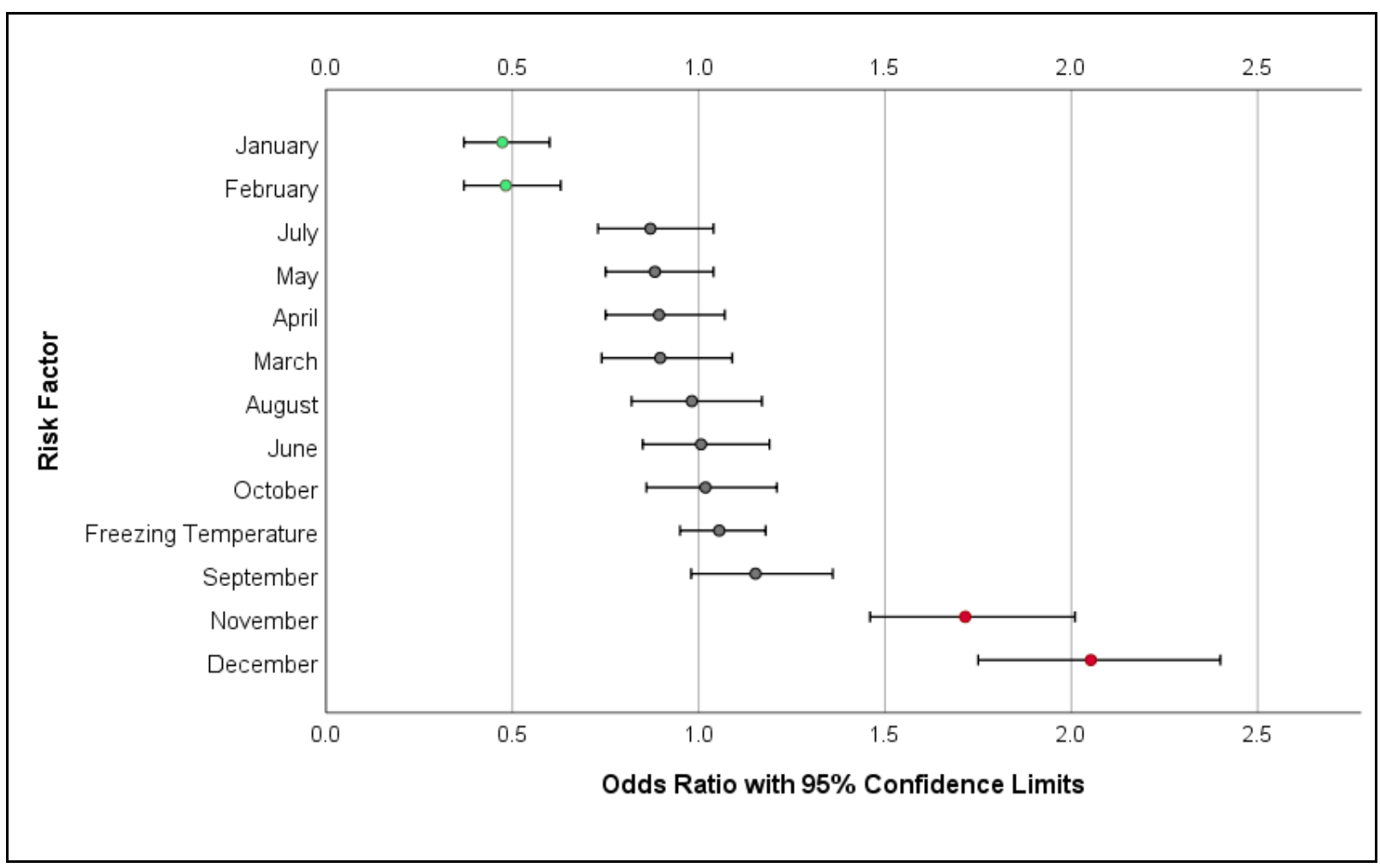

Figure 2 with Data Table: Odds of Fall Injury with 95\% Confidence Intervals by Month of Injury and by Day of Freezing Temperature. Fall Injury from Syndromic Surveillance Discharge Data with ICD10 Code of W00-W19.

\begin{tabular}{|c|c|c|c|c|c|c|c|}
\hline Risk Factor & $\begin{array}{c}\text { Injured } \\
- \\
\text { Expose } \\
\text { d }\end{array}$ & $\begin{array}{c}\text { No } \\
\text { Injury- } \\
\text { Expose } \\
\text { d }\end{array}$ & $\begin{array}{c}\text { Injured } \\
- \\
\text { Unexpo } \\
\text { sed }\end{array}$ & $\begin{array}{c}\text { No } \\
\text { Injury- } \\
\text { Unexpo } \\
\text { sed }\end{array}$ & $\begin{array}{l}\text { Odds } \\
\text { Ratio }\end{array}$ & $\begin{array}{c}\text { Lower } \\
\text { CL }\end{array}$ & $\begin{array}{c}\text { Upper } \\
\text { CL }\end{array}$ \\
\hline January & 71 & 1192 & 1704 & 13539 & 0.47 & 0.37 & 0.6 \\
\hline February & 63 & 1044 & 1712 & 13687 & 0.48 & 0.37 & 0.63 \\
\hline March & 121 & 1111 & 1654 & 13620 & 0.9 & 0.74 & 1.09 \\
\hline April & 140 & 1288 & 1635 & 13443 & 0.89 & 0.75 & 1.07 \\
\hline May & 167 & 1551 & 1608 & 13180 & 0.88 & 0.75 & 1.04 \\
\hline June & 163 & 1345 & 1612 & 13386 & 1.01 & 0.85 & 1.19 \\
\hline July & 146 & 1375 & 1629 & 13356 & 0.87 & 0.73 & 1.04 \\
\hline August & 152 & 1283 & 1623 & 13448 & 0.98 & 0.82 & 1.17 \\
\hline September & 178 & 1299 & 1597 & 13432 & 1.15 & 0.98 & 1.36 \\
\hline October & 160 & 1306 & 1615 & 13425 & 1.02 & 0.86 & 1.21 \\
\hline November & 199 & 1010 & 1576 & 13721 & 1.72 & 1.46 & 2.01 \\
\hline December & 215 & 927 & 1560 & 13804 & 2.05 & 1.75 & 2.4 \\
\hline $\begin{array}{l}\text { Freezing } \\
\text { Temperature }\end{array}$ & 506 & 4040 & 1269 & 10691 & 1.06 & 0.95 & 1.18 \\
\hline
\end{tabular}




\section{Diagnostic Efficacy of Case-Control Compared to Cohort Analysis}

Using count data for each indicator variable from those with accidental fall injuries and those without, 9 of the 14 geocoded zip code areas were true predictors of increases when the more efficient case control study was used. With gender and age predictors were examined the preponderance of the risk ratios (12 out of the 13) were true predictors of increased risk. The sensitivity (the true positive rate) of the 'fall injuries ICD10 W00-W19' syndromic surveillance data in an unmatched case control study in lieu of population data will identify a risk factor in the population $62.5 \%$ (95\% CI 24.5-91.5) of the time when the risk factor is present. The specificity (the true negative rate) of the fall injuries ICD10 W00-W19 syndromic surveillance data to be used in an unmatched case control study in lieu of population data was $84.2 \%$ (60.496.6). The accuracy was $77.7 \%$ (57.7-91.3).

Table 1: Fall Injuries Identified by Syndromic Surveillance ICD10 Codes W00-W19 in Greene County Residents during 2018 by Risk Factor using Population Estimates for Risk Calculations or Patients with Traumatic Injuries as Controls for Odds Ratio Calculations.

\begin{tabular}{|c|c|c|c|c|c|c|}
\hline Risk Factor & \begin{tabular}{|l|} 
Fall \\
Injury \\
Exposed \\
{$[1]$}
\end{tabular} & $\begin{array}{l}\text { No Fall } \\
\text { Exposed }\end{array}$ & $\begin{array}{l}\text { Fall } \\
\text { Injury } \\
\text { Unexpose } \\
\text { d }\end{array}$ & $\begin{array}{l}\text { No Fall } \\
\text { Unexpose } \\
\text { d }\end{array}$ & $\begin{array}{l}\text { Controls } \\
\text { No Fall } \\
\text { Exposed }\end{array}$ & $\begin{array}{l}\text { Controls } \\
\text { No Fall } \\
\text { Unexpose } \\
\text { d }\end{array}$ \\
\hline zip 45305 & 61 & 10930 & 1714 & 147919 & 690 & 14041 \\
\hline zip 45307 & 1 & 321 & 1775 & 158528 & 38 & 14693 \\
\hline zip 45314 & 16 & 5853 & 1759 & 152996 & 234 & 14497 \\
\hline zip 45324 & 445 & 38407 & 1330 & 120442 & 2735 & 11996 \\
\hline zip 45335 & 31 & 6652 & 1744 & 152197 & 894 & 13837 \\
\hline zip 45370 & 16 & 2537 & 1759 & 156312 & 160 & 14571 \\
\hline zip 45385 & 491 & 37724 & 1284 & 121125 & 3916 & 10815 \\
\hline zip 45387 & 56 & 5057 & 1719 & 153792 & 339 & 14392 \\
\hline zip 45430 & 73 & 7143 & 1702 & 151706 & 544 & 14187 \\
\hline zip 45431 & 181 & 13370 & 1594 & 145479 & 1973 & 12758 \\
\hline zip 45432 & 134 & 7977 & 1641 & 150872 & 1124 & 13607 \\
\hline zip 45433 & 3 & 2460 & 1772 & 156389 & 45 & 14686 \\
\hline zip 45434 & 75 & 11718 & 1700 & 147131 & 645 & 14086 \\
\hline zip 45440 & 193 & 8700 & 1582 & 150149 & 1394 & 13337 \\
\hline Female gender & 1185 & 81148 & 590 & 77701 & 7531 & 7200 \\
\hline Male gender & 590 & 77701 & 1185 & 81148 & 7200 & 7531 \\
\hline Age Group $=<1$ & 8 & 1866 & 1767 & 156983 & 131 & 14600 \\
\hline Age Group 1-4 & 26 & 7469 & 1749 & 151380 & 1134 & 13597 \\
\hline Age group 5-14 & 43 & 18622 & 1732 & 140227 & 2294 & 12437 \\
\hline
\end{tabular}




\begin{tabular}{|l|r|r|r|r|r|r|}
\hline $\begin{array}{l}\text { Age Group 15- } \\
24\end{array}$ & 59 & 24248 & 1716 & 134601 & 1974 & 12757 \\
\hline $\begin{array}{l}\text { Age Group 25- } \\
34\end{array}$ & 85 & 21370 & 1690 & 137479 & 1609 & 13122 \\
\hline $\begin{array}{l}\text { Age Group 35- } \\
44\end{array}$ & 79 & 17732 & 1696 & 141117 & 1402 & 13329 \\
\hline $\begin{array}{l}\text { Age Group 45- } \\
54\end{array}$ & 105 & 20611 & 1670 & 138238 & 1358 & 13373 \\
\hline $\begin{array}{l}\text { Age Group 55- } \\
64\end{array}$ & 234 & 21850 & 1541 & 136999 & 1499 & 13232 \\
\hline $\begin{array}{l}\text { Age Group 65- } \\
74\end{array}$ & 296 & 14849 & 1479 & 144000 & 1302 & 13429 \\
\hline $\begin{array}{l}\text { Age Group 75- } \\
84\end{array}$ & 494 & 7343 & 1381 & 151506 & 1128 & 13603 \\
\hline $\begin{array}{l}\text { Age Group 85 } \\
\text { plus }\end{array}$ & 2889 & 1329 & 155960 & 900 & 13831 \\
\hline
\end{tabular}

1. Exposed to the risk factor.

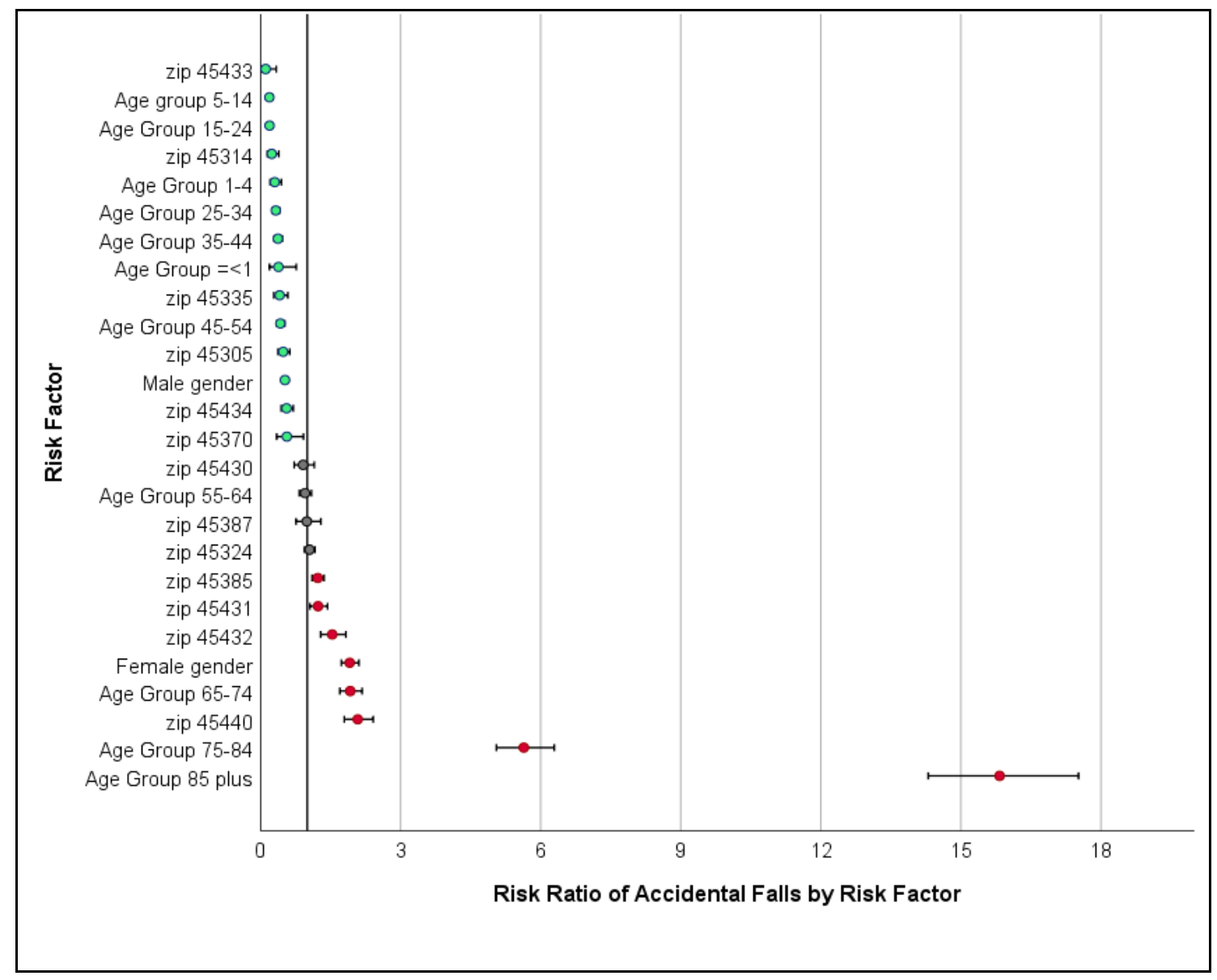

Figure 3 with Data Table Evaluation of Odds Ratio to Predict Risk of Fall Injuries Among Greene County Residents Fall Injuries during Year 2018. 


\begin{tabular}{|c|c|c|c|c|c|c|c|}
\hline Risk Factor & $\begin{array}{l}\text { Odds } \\
\text { Ratio }\end{array}$ & $\begin{array}{c}\text { OR } \\
\mathbf{L C L}\end{array}$ & $\begin{array}{c}\text { OR } \\
\text { UCL }\end{array}$ & $\begin{array}{l}\text { Risk } \\
\text { Ratio }\end{array}$ & $\begin{array}{c}\mathbf{R R} \\
\mathbf{L C L}\end{array}$ & $\begin{array}{c}\mathbf{R R} \\
\mathbf{U C L}\end{array}$ & $\begin{array}{l}\text { Diagnostic } \\
\text { Evaluation of } \\
\text { Odds Ratio }\end{array}$ \\
\hline zip 45305 & 0.72 & 0.55 & 0.95 & 0.48 & 0.38 & 0.63 & True Negative \\
\hline zip 45307 & 0.22 & 0.01 & 3.6 & 0 & & & True Negative \\
\hline zip 45314 & 0.56 & 0.34 & 0.94 & 0.24 & 0.15 & 0.39 & True Negative \\
\hline zip 45324 & 1.47 & 1.31 & 1.65 & 1.05 & 0.94 & 1.17 & False Positive \\
\hline zip 45335 & 0.28 & 0.19 & 0.39 & 0.41 & 0.29 & 0.58 & True Negative \\
\hline zip 45370 & 0.83 & 0.49 & 1.39 & 0.56 & 0.35 & 0.92 & True Negative \\
\hline zip 45385 & 1.06 & 0.95 & 1.18 & 1.23 & 1.11 & 1.36 & False Negative \\
\hline zip 45387 & 1.38 & 1.04 & 1.84 & 0.99 & 0.76 & 1.29 & False Positive \\
\hline zip 45430 & 1.12 & 0.87 & 1.44 & 0.91 & 0.72 & 1.15 & True Negative \\
\hline zip 45431 & 0.73 & 0.63 & 0.86 & 1.23 & 1.06 & 1.44 & False Negative \\
\hline zip 45432 & 0.99 & 0.82 & 1.19 & 1.54 & 1.29 & 1.83 & False Negative \\
\hline zip 45433 & 0.55 & 0.17 & 1.78 & 0.11 & 0.04 & 0.34 & True Negative \\
\hline zip 45434 & 0.96 & 0.75 & 1.23 & 0.56 & 0.44 & 0.7 & True Negative \\
\hline zip 45440 & 1.17 & 1 & 1.37 & 2.08 & 1.8 & 2.41 & True Positive \\
\hline Female gender & 1.92 & 1.73 & 2.13 & 1.91 & 1.73 & 2.11 & True Positive \\
\hline Male gender & 0.52 & 0.47 & 0.58 & 0.52 & 0.48 & 0.58 & True Negative \\
\hline Age Group $=<1$ & 0.5 & 0.25 & 1.03 & 0.38 & 0.19 & 0.77 & True Negative \\
\hline Age Group 1-4 & 0.18 & 0.12 & 0.26 & 0.3 & 0.21 & 0.45 & True Negative \\
\hline Age group 5-14 & 0.13 & 0.1 & 0.18 & 0.19 & 0.14 & 0.26 & True Negative \\
\hline Age Group 15-24 & 0.22 & 0.17 & 0.29 & 0.19 & 0.15 & 0.25 & True Negative \\
\hline Age Group 25-34 & 0.41 & 0.33 & 0.51 & 0.33 & 0.26 & 0.41 & True Negative \\
\hline Age Group 35-44 & 0.44 & 0.35 & 0.56 & 0.37 & 0.3 & 0.47 & True Negative \\
\hline Age Group 45-54 & 0.62 & 0.5 & 0.76 & 0.43 & 0.35 & 0.52 & True Negative \\
\hline Age Group 55-64 & 1.34 & 1.16 & 1.55 & 0.95 & 0.83 & 1.09 & False Positive \\
\hline Age Group 65-74 & 2.06 & 1.8 & 2.37 & 1.92 & 1.7 & 2.18 & True Positive \\
\hline Age Group 75-84 & 3.44 & 3.03 & 3.91 & 5.64 & 5.05 & 6.29 & True Positive \\
\hline Age Group 85 plus & 5.16 & 4.54 & 5.85 & 15.83 & 14.3 & 17.52 & True Positive \\
\hline
\end{tabular}

Figure 3 Data Table Evaluation of Odds Ratio to Predict Risk of Fall Injuries Among Greene County Residents Fall Injuries during Year 2018.

\section{DISCUSSION}

An advantage of the case-control design is that the controls can be matched to the cases by date, sex, zip code area, and age. While population risk factors can be matched on zip code area this 
is done using the American Community Survey's annual population estimates and applying the decennial census' zip code population's proportion within the jurisdiction of interest. This estimate of risk would be subject to the margin of error of those estimates and widened by the application of the earlier decennial zip code population proportion factor.

The log of two risk estimates and their confidence interval should be taken to evaluate if two separate and independent risk ratios are different [10]. We did not compare risk ratios to each other rather, we compared two methods and their overall results using sensitivity and specificity analysis.

While our research found higher risk in females and a protective effect among males (Figure 3), earlier research identified inpatient males having higher risk for injurious falls (odds 2.08) [7]. We evaluated the risk of falls for the entire community of over 160,000 persons not just inpatients. If both findings are to be believed, then a logical explanation is that most fall injuries among females occur before admission, leaving a surplus of male inpatients to subsequently fall after admission for other injuries. The interplay of treatment effects on stability and the hospital staff's perception of risk and initiation of fall prevention precautions are potential issues to explore regarding the quality of care among inpatient males. These other issues provide for both these findings to be valid. Also, our findings are consistent with a study of persons 65 years and older age that found female sex was associated with an increased risk of falls and fear of falling [11].

Our study also revealed that January and February fall injuries were much lower than other months. Indeed, these two months were revealed as having a protective odds of fall injury requiring acute care. One explanation is regression to the mean. With so many injuries occurring during the holiday months of November and December, perhaps the pool of person who are susceptible to fall injury have already occurred early during the start of the winter months. Of interest in that study is that most falls occurred while walking. This is supportive of our findings that those persons in the later three age groups starting at 65 years and older are at elevated risk. This is consistent with an etiology of the elderly out walking while visiting friends and relatives during the holidays in November and December during a time when icy conditions are variable increase susceptibility to falls. The higher case fatality rate during days with freezing temperature is consistent with this proposed etiology. Specifically, this study found that during any freezing temperature have a higher case fatality rate among all those with fall injury.

Essentially all those who were residents of the community who were injured enough to seek acute care were included in our study. Only those who sought care outside of the entire state would have been missed. We assume this number was near zero. We analyzed data for all the county residents no matter where they were treated within Ohio. Our findings of a low predictive value of odds ratios is consistent with fall assessment tools applied to hospitalized patients [7]. We did not have information on a person's history of falls, but we did have information on the number of repeat acute care interactions per year. This value was congruent with the odds seen in hospitalized patients. Others have studied the rate of return for fall injury from date of discharge for 1 month (2.6\%), 3 months (6.3\%), 12 months $(9.1 \%)$, and 2 years (13.4\%) [12]. We studied the entire population, not just those who were discharged, these separate and distinct finding are consistent with the concept that increasing need for health care services are associated with rising risks of injury from falls. Our finding of rising risk of falls with repeat acute care interactions suggests a biological gradient and a strength of association that supports a causal association. A 2014 study had analogous results of a categorical gradient 
with the use of more than one benzodiazepine or sedative hypnotic medication found to increase the risk of falls [13]. Other research found an increase in odds of fall injury with increasing the number of drugs increased the odds for fall injury after discharge, 1.03 (1.021.04) [12].

\section{PUBLIC HEALTH IMPLICATIONS}

The risk of falling has been shown to be able to be reduced through application of interventions based on data from risk calculations [12,14]. Diagnosis of fall injuries agreed with free text reasons for acute care. A case control design can provide efficiencies through ease of matching indicator variables of date and area for public health surveillance of fall injuries but at a relative cost of the resulting specificity $(84.2 \%)$, sensitivity (62.5\%), and accuracy (77.7\%). The value of a case control design is the provision of valuable data on the odds from exposure to a risk factor and it can do so quickly. Community fall injury risks differed from inpatient studies for gender. The case control diagnostic quality of fall injuries was better for age and gender than for residential zip code. Freezing temperature increased the fall injury case fatality rate. Community risk factors for fall injuries included repeat visits for acute care $(6.47 \%$ for every additional visits, trending $\mathrm{R}=.333, \mathrm{p}<.001$ ), month of year, age group 65-74 years (OR 1.9,1.72.18), 75-84 years (OR 5.6, 5.05-6.29), and 85 plus years (OR 15.8, 14.3-17.52), and female gender (OR 1.9, 1.73-2.11). The use of EpiCenter for fall injury surveillance provides a useful source of data for local public health agencies. The finding that a gradient of increasing odds of fall injuries with the number of visits for acute care is a strong indicator for causality, suggesting community fall prevention programs should also focus on those most likely to fall as well as other targeted population segments.

\section{Financial Disclosures}

The authors have no financial interests to disclose.

\section{References}

1. The Health Collaborative, Greater Data Hospital Association. (2019). SW Ohio, N Kentucky, SE Indiana CHNA Community Health Needs Assessment. 2019 Report.

2. Dockery J, Murray C, Sullivan M, Gill J, Hartley B, et al. (2017). Greene County Community Health Assessment, 2017. A. Steveley, (Ed). Greene County Public Health and the Wright State University, Applied Policy Research Institute, August 10, 2017, Xenia, OH. DOI: https://doi.org/10.13140/RG.2.2.27794.91845

3. Greene County Public Health. (2017). Community Health Improvement Plan 2017. A. Steveley, (Ed). Greene County Community Health Improvement Steering Committee and Work Group Members. Plan Adoption Date November 2, 2017.

4. Seil K, Marcum J, Lall R, Stayton C. 2015. Utility of a near real-time emergency department syndromic surveillance system to track injuries in New York City. Inj Epidemiol. 2(1), 11. doi:https://doi.org/10.1186/s40621-015-0044-5. PubMed

5. Health Monitoring Systems. 2019. EpiCenter. March 1, 2019. https://www.healthmonitoring.com/syndromic-surveillance-epicenter/ 
6. ODH. (2019). Ohio Public Health Information Warehouse. Secure Ohio Public Health Information Warehouse Version 1.1 Ohio Resident Mortality Data, 2018. These data were provided by the Ohio Department of Health. The Department specifically disclaims responsibility for any analyses, interpretations or conclusions. http://publicapps.odh.ohio.gov/EDW/DataCatalog

7. Aryee E, James SL, Hunt GM, Ryder HF. 2017. Identifying protective and risk factors for injurious falls in patients hospitalized for acute care: a retrospective case-control study. BMC Geriatr. 17(1), 260. doi:https://doi.org/10.1186/s12877-017-0627-9. PubMed

8. Gevitz K, Madera R, Newbern C, Lojo J, Johnson CC. 2017. Risk of Fall-Related Injury due to Adverse Weather Events, Philadelphia, Pennsylvania, 2006-2011. Public Health Rep. 132(1) (suppl), 53S-58S. doi:https://doi.org/10.1177/0033354917706968. PubMed

9. NOAA. National Oceanic and Atmospheric Administration, National Centers for Environmental Information. Location Details Greene County, OH, ID FIPS 39057, Period of Record, 2018-01-01 to 2018-12-31. https://www.ncdc.noaa.gov/cdo-web/results

10. Altman DG, Bland JM. 2003. Interaction revisited: the difference between two estimates. BMJ. 326(7382). PubMed https://doi.org/10.1136/bmj.326.7382.219

11. Gazibara T, Kurtagic I, Kisic-Tepavcevic D, Nurkovic S, Kovacevic N, et al. 2017. Falls, risk factors and fear of falling among persons older than 65 years of age. Psychogeriatrics. 17(4), 215-23. Epub Jan 2017. doi:https://doi.org/10.1111/psyg.12217. PubMed

12. Castro VM, McCoy TH, Cagan A, et al. Stratification of risk for hospital admissions for injury related to fall: cohort study. BMJ. 2014;349:g5863. Published 2014 Oct 24. doi:https://doi.org/10.1136/bmj.g5863

13. Helgadóttir B, Laflamme L, Monárrez-Espino J, Möller J.Medication and fall injury in the elderly population; do individual demographics, health status and lifestyle matter? BMC Geriatr. 2014 Aug 23;14:92. doi: https://doi.org/10.1186/1471-2318-14-92. PMCID: PMC4150120 Free PMC Article PMID: 25151122

14. Yokota S, Tomotaki A, Mohri O, Endo M, Ohe K. 2016. Evaluation of a Fall Risk Prediction Tool Using Large-Scale Data. Stud Health Technol Inform. 225, 800-01. $\underline{\text { PubMed }}$ 